\title{
Perioperative management of left ventricular diastolic dysfunction and heart failure: an anesthesiologist's perspective
}

\author{
Taeha Ryu and Seok-Young Song \\ Department of Anesthesiology and Pain Medicine, School of Medicine, Catholic University of Daegu, Daegu, Korea
}

\begin{abstract}
Anesthesiologists frequently see asymptomatic patients with diastolic dysfunction or heart failure for various surgeries. These patients typically show normal systolic function but abnormal diastolic parameters in their preoperative echocardiographic evaluations. The symptoms that are sometimes seen are similar to those of chronic obstructive pulmonary disease. Patients with diastolic dysfunction, and even with diastolic heart failure, have the potential to develop a hypertensive crisis or pulmonary congestion. Thus, in addition to conventional perioperative risk quantification, it may be important to consider the results of diastolic assessment for predicting the postoperative outcome and making better decisions. If anesthesiologists see female patients older than 70 years of age who have hypertension, diabetes, chronic renal disease, recent weight gain, or exercise intolerance, they should focus on the patient's diastologic echocardiography indicators such as left atrial enlargement or left ventricular hypertrophy. In addition, there is a need for perioperative strategies to mitigate diastolic dysfunction-related morbidity. Specifically, hypertension should be controlled, keeping pulse pressure below diastolic blood pressure, maintaining a sinus rhythm and normovolemia, and avoiding tachycardia and myocardial ischemia. There is no need to classify these diastolic dysfunction, but it is important to manage this condition to avoid worsening outcomes.
\end{abstract}

Key Words: Diastolic dysfunction, Echocardiography, Heart failure, Perioperative strategies.

\section{Introduction}

The efficiency and function of the left ventricle (LV) as a

Corresponding author: Seok-Young Song, M.D., Ph.D.

Department of Anesthesiology and Pain Medicine, School of Medicine, Catholic University of Daegu, 33, Duryugongwon-ro 17gil, Namgu, Daegu 42472, Korea

Tel: 82-53-650-4502, Fax: 82-0303-3442-4885

Email: anessy73@cu.ac.kr

ORCID: http://orcid.org/0000-0002-5653-7005

Received: October 17, 2016.

Revised: December 19, 2016.

Accepted: December 19, 2016.

Korean J Anesthesiol 2017 February 70(1): 3-12 https://doi.org/10.4097/kjae.2017.70.1.3 pump are represented as systole and diastole. The systolic function is energy dependent; the diastolic function is an important part of cardiac output (as preload) and also includes active processes such as the suction effect, which is also energy dependent and can be weakened by ischemia [1,2]. Thus, diastolic dysfunction (DDf) is an early marker of ischemia, because it is sensitive to impaired perfusion $[3,4]$.

Most physicians pay attention to the LV ejection fraction (EF) for systolic function in the preoperative echocardiographic evaluation of patients about to undergo surgery; however, LV DDf is often overlooked in such cardiac risk evaluation. LV DDf, and even diastolic heart failure (DHF), are usually not significant problems in the daily life of patients who do not suffer from exercise intolerance, dyspnea, or pulmonary edema. However, when they reach the ward after an operation, they often end up in the intensive care unit (ICU) with unstable vital signs in com-

(c) This is an open-access article distributed under the terms of the Creative Commons Attribution Non-Commercial License (http://creativecommons.org/ licenses/by-nc/4.0/), which permits unrestricted non-commercial use, distribution, and reproduction in any medium, provided the original work is properly cited. 
bination with pulmonary edema, which are not responsive to the normal use of intravenous (IV) epinephrine or norepinephrine. This can lead to poor outcomes, caused by LV DDf regardless of LV systolic dysfunction (SDf), with hemodynamic instability developing due to surgery-induced adrenergic stimulation and anesthesia-induced sympathetic attenuation [5], resulting in a lengthy stay in the ICU or even death.

In American Heart Association-American College of Cardiology (AHA-ACC) guidelines, LV DDf is still underestimated in preoperative risk assessment and few clinical data supporting its importance are available [6]. In particular, such patients need more appropriate anesthetic management to prevent postoperative complications and to aid in recovery from anesthesia. Because overlooking patients with LV DDf or LV DHF during the perioperative period, regardless of LV systolic function, can be very dangerous and cause poor outcomes, it is important that anesthesiologists are familiar with the pathophysiology, management, and surgical outcomes and are able to notice their phenotypic characteristics, and diagnostic parameters.

\section{Definitions}

Regardless of LV systolic function and the patient's symptoms, DDf indicates impaired filling of the ventricles at low pressure and abnormalities in diastolic distensibility, filling, or relaxation, which are usually associated with hypertension, diabetes, or ischemia [7]. The diagnosis of DDf can come from cardiac catheterization and Doppler patterns of LV diastolic filling. DDf shows increased LV diastolic pressure (> $16 \mathrm{mmHg})$ with preserved systolic function and LV volume [8]. DDf itself is a physiological or preclinical state that can be compensated for with an increase in left atrial pressure, so there is essentially an asymptomatic period. In addition to echocardiographic or angiographic evidence, when accompanied by symptoms and signs that can be confused with chronic obstructive pulmonary disease such as exercise intolerance, exertional dyspnea, and pulmonary edema with normal EF, it could be considered DHF

Table 1. Criteria for Diastolic Heart Failure

1. Signs and symptoms of congestive heart failure:
pulmonary edema, effort dyspnea, orthopnea
2. Normal or mildly reduced EF
$\mathrm{EF}>50 \%$, normal LV end diastolic volume
3. Abnormal LV relaxation
Echocardiographic tissue Doppler $\left(\mathrm{E} / \mathrm{E}^{\prime}>15\right)$
LVEDP $>16 \mathrm{mmHg}$ on cardiac catheterization
Biomarkers NT-proBNP $>220 \mathrm{pg} / \mathrm{ml}$ or BNP $>200 \mathrm{pg} / \mathrm{ml}$

All three criteria are required for the diagnosis of diastolic heart failure. EF: ejection fraction, LV: left ventricle, LVEDP: left ventricular enddiastolic pressure, NT-proBNP: N-terminal pro B-type Natriuretic Peptide, BNP: brain natriuretic peptide (B-type Natriuretic Peptide).
$[9,10]$. DHF is also characterized by a stiff and thickened ventricle, with a small cavity and low cardiac output. About half of congestive heart failure cases have a normal EF. DHF can also show a normal EF; this is called heart failure with a normal ejection fraction (HFnEF) or preserved EF (HFpreEF) [11]. However, DDf can also accompany SDf (Table 1).

\section{Epidemiology}

In preclinical DDf, hypertension, hyperlipidemia, coronary artery disease, and renal dysfunction are prevalent. In one study, the 2-year cumulative probability of developing any symptom was as high as $31 \%$ and the probability of cardiac hospitalization was $21 \%$ [12]. Asymptomatic DDf is generally common in patients without heart failure, increases with age, and is particularly seen in elderly women with hypertension and hypertrophy of the ventricle [13]. DDf alone can predict worse outcomes in patients and their prognosis worsens according to its increasing degree [13]. Moreover, more than half of all patients with heart failure have a normal EF [14,15]. Compared to SDf, the incidence and prevalence of DDf are increasing [14,16], and in geriatric patients in particular, it can cause hospitalization, increasing hospital costs [17], and even mortality [15]. A study of two cohorts of patients with decompensated heart failure showed that 35\% had preserved LV EF and that they were elderly and mainly women [18]. Phillip et al. [19] reported that $\sim 60 \%$ of elderly patients with normal EF presenting for geriatric cardiac and non-cardiac surgery had LV-filling abnormalities. Moreover, $\sim 15 \%$ of these patients had moderate to severe DDf in the absence of symptoms. In patients undergoing high-risk vascular surgery, DDf is common, 43\% [20]. DHF increased proportionally with age, up to $70 \%$ in those aged $>70$ years [21]. There are also age-related changes in the cardiovascular system including coronary artery disease, systemic hypertension, and hypertrophic or infiltrative cardiomyopathy. The effects of these conditions can also increase filling pressure due to abnormalities in relaxation and decreased compliance of the LV [8].

\section{Pathophysiology}

Diastole can be divided into four stages: isovolumetric ventricular relaxation, rapid passive ventricular filling, diastasis, and atrial contraction [22]. These can also be subdivided into early and late phases. In the isovolumetric relaxation period, after mitral valve closure, calcium is sequestered back into the sarcoplasmic reticulum; this is an active process for the suction effect, which needs adenosine triphosphate (ATP) [7]. In DDf, the breakdown of this process causes the ventricle to fail to relax and become stiff/less compliant. This dysfunction can be caused by impaired LV compliance, a passive process, or by changes in 
LV active relaxation [7].

Anatomical diastole occurs from aortic valve closing to mitral valve closing, but at the molecular level, relaxation of the LV starts during the early systolic period, because it starts with the dissociation of actin-myosin cross bridges [23]. This indicates that relaxation and contraction are intimately coupled. Because LV segmental and atrio-ventricular synchronization are indispensable in guaranteeing effective relaxation, loss of the atrial kick in atrial fibrillation not only changes LV filling but also slows myocardial relaxation [24]. Before Doppler-derived variables, the gold-standard measurement of LV diastolic function was the invasive measurement of LV pressures using cardiac catheterization [25]. This can show pressure/volume loops, LV pressure decline, and the time constant of isovolumetric relaxation $(\tau)$. DHF patients typically show a significant increase in $\tau$ [26]. In pressure/volume loops, LV DDf shows a diastolic loop (compliance curve) shifted to the left and upwards. In such cases, LV end-diastolic volume is normal but end-diastolic pressure is increased, resulting in pulmonary congestion. However, SDf causes the end-systolic slope to shift to the right and downwards [7] (Fig. 1). In active diastole with isovolumetric relaxation, which is energy dependent, abnormalities in relaxation can be caused by myocardial ischemia, hypertension, aortic stenosis, and hypertrophic cardiomyopathy. In contrast, passive diastole can be impaired by increased stiffness of the LV chamber, caused by an infiltrative disorder (amyloidosis), myocardial fibrosis, and progression from impaired relaxation.

Age-related changes in the cardiovascular system can be condensed into a reduction of cardiovascular reserve, which includes increased arterial and myocardial stiffness, impaired $\beta$-adrenergic responsiveness and LV relaxation, and reduced sinus nodal function and baroreceptor responsiveness [8,27]. Aging is related to ventricular and arterial stiffness, which increase and exacerbate myocardial oxygen consumption for cardiac output $[28,29]$. Apoptotic myocytes are not replaced, but decrease in number with an increased amount of connective tis- sue matrix. The afterload causes increased arterial stiffness that affects LV relaxation [30], resulting in ventricular hypertrophy to preserve systolic function [29]. Age-related arterial stiffening has two important consequences: decreased aortic distensibility and increased pulse wave velocity $[31,32]$, which result in higher pulse pressure (PP) and prolonged systolic contraction $[33,34]$, respectively. Increased PP is an established cardiovascular risk factor [35-38] and the early reflected wave, because of prolonged systolic contraction, impinges on early diastole, which can cause greater myocardial stroke work, wall strain, and oxygen consumption such as a mistimed intra-aortic balloon pump. Beyond this, impaired calcium homeostasis and reduced $\beta$-receptor responsiveness also cause LV DDf. At the cellular level, reduced sarcoplasmic/endoplasmic reticulum calcium ATPase 2 (SERCA2) activity and increased phospholamban activity contribute to impaired LV diastolic function [39-41]. The signal dampening of $\beta$-receptors may be due to receptor downregulation or diminished coupling of $\beta$-receptors with intracellular adenylate cyclase activity [42-44]. Consequently, despite increased circulating catecholamines, there is a limited increase in heart rate and contractility in response to endogenous and exogenous catecholamines, so there is impaired baroreflex control of blood pressure (BP). Apoptosis, fibrosis, fatty infiltration, and calcification of pacemaker and His-bundle cells can result in conduction block, sick sinus syndrome, and arterial fibrillation, with loss of the atrial kick for preload in the end-diastole stage [5]. Arrhythmias (e.g., atrial fibrillation) and myocardial ischemia affecting diastolic timing can decompensate pre-existing DDf further. Tachycardia shortens diastole and can impair LV filling. Treatment with $\beta$ blockers or calcium channel blockers has been recommended to control tachycardia or arrhythmias to improve LV filling $[45,46]$.

\section{Perioperative Clinical Assessment}

Patients with DDf in the operating room have some common
A

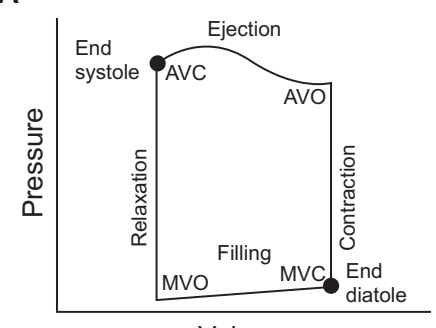

B

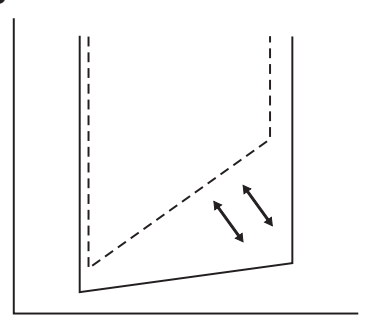

C

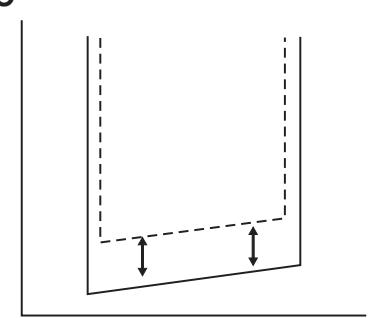

D

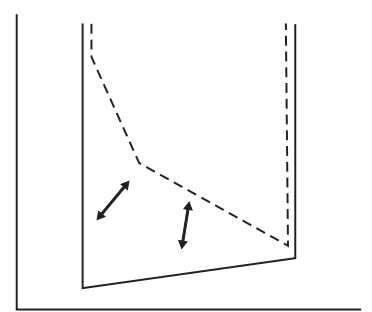

Fig. 1. (A) Left ventricular pressure/volume curve shows the relationship between systole and diastole through a microneedle with a manometer as the gold standard measurement of heart function. (B) Increased chamber stiffness makes the curve of the late diastolic period shift upwards and left. (C) Pericardial restraint makes the whole diastolic curve shift upward. (D) Abnormal or impaired relaxation of ventricle makes the early diastolic curve, including isovolumetric relaxation, shift upwards and right. 
phenotypic characteristics such as being elderly women and having peripheral edema, hypertension, and obesity. They also tend to have limitations in functional capacity caused by reduced chronotropic, vasodilator, and cardiac reserve. In addition to a functional capacity evaluation, risk factors and phenotypes for heart failure should be checked in the preoperative assessment for DDf because a heart failure history alone is associated with increased morbidity and mortality after non-cardiac surgery [27] (Table 2).

Biomarkers of DDf are important as prognostic parameters in patients with myocardial ischemia, atrial fibrillation, aortic stenosis, and general heart failure. Cardiac catheterization can

Table 2. Risk Factors for Diastolic Heart Failure in Preoperative Anesthetic Evaluation

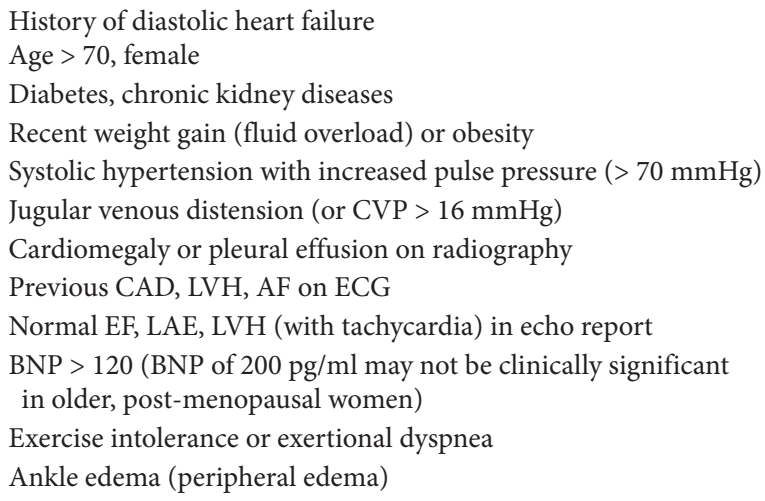

CVP: central venous pressure, CAD: coronary artery disease, LVH: left ventricular hypertrophy, AF: atrial fibrillation, ECG: electrocardiography, LAE: left atrial enlargement, BNP: brain natriuretic peptide. show increased ventricular diastolic pressure $(>16 \mathrm{mmHg})$ with preserved systolic function and normal ventricular volumes in DDf [8]. Beyond the analysis of pressure/volume curves from cardiac catheterization, echocardiographic assessment of diastolic function becomes very important in perioperative risk stratification, surgical care, and anesthetic management of patients undergoing operations [10]. However, before considering echocardiographic findings, the different application of variables in transthoracic echocardiography (TTE) and transesophageal echocardiography (TEE) in the outpatient clinic from intraoperative TEE should be acknowledged because of differences in the postures of patients and their ventilation status, as well as the effects of anesthetic drugs [47]. The classification and assessment of DDf comes from the initial, transmitral flow (TMF) examination with a pulsed-wave Doppler (PWD)-based evaluation of LA and LV filling and its abnormalities, according to current guidelines. However, because of the known limitations of the rigid application of conventional Doppler indices [22,48-50], the most recent guidelines no longer recommend determining $\mathrm{E}$ and A waves on TMF with PWD as the initial step in the decision for grading DDf with normal LV EF [51]. New guidelines based on TTE have been simplified and focus on the increase in left atrial pressure (LAP) rather than grading diastolic dysfunction. In patients with normal LV EF, more than half of the following should be positive to determine the presence of DDf: average $\mathrm{E} \mathrm{E}^{\prime}>14$, lateral $\mathrm{E}^{\prime}<10 \mathrm{~cm} / \mathrm{s}$, tricuspid regurgitation (TR) velocity $>2.8 \mathrm{~m} / \mathrm{s}$, and LA volume index $>34 \mathrm{ml} / \mathrm{m}^{2}$. In patients with depressed LV EF and with normal LV EF but myocardial disease, the mitral inflow ratio and the criteria above are used for evaluating LAP and grading DDf (Table 3).

Table 3. New Guidelines for Diagnosis of LV Diastolic Dysfunction Based on TTE

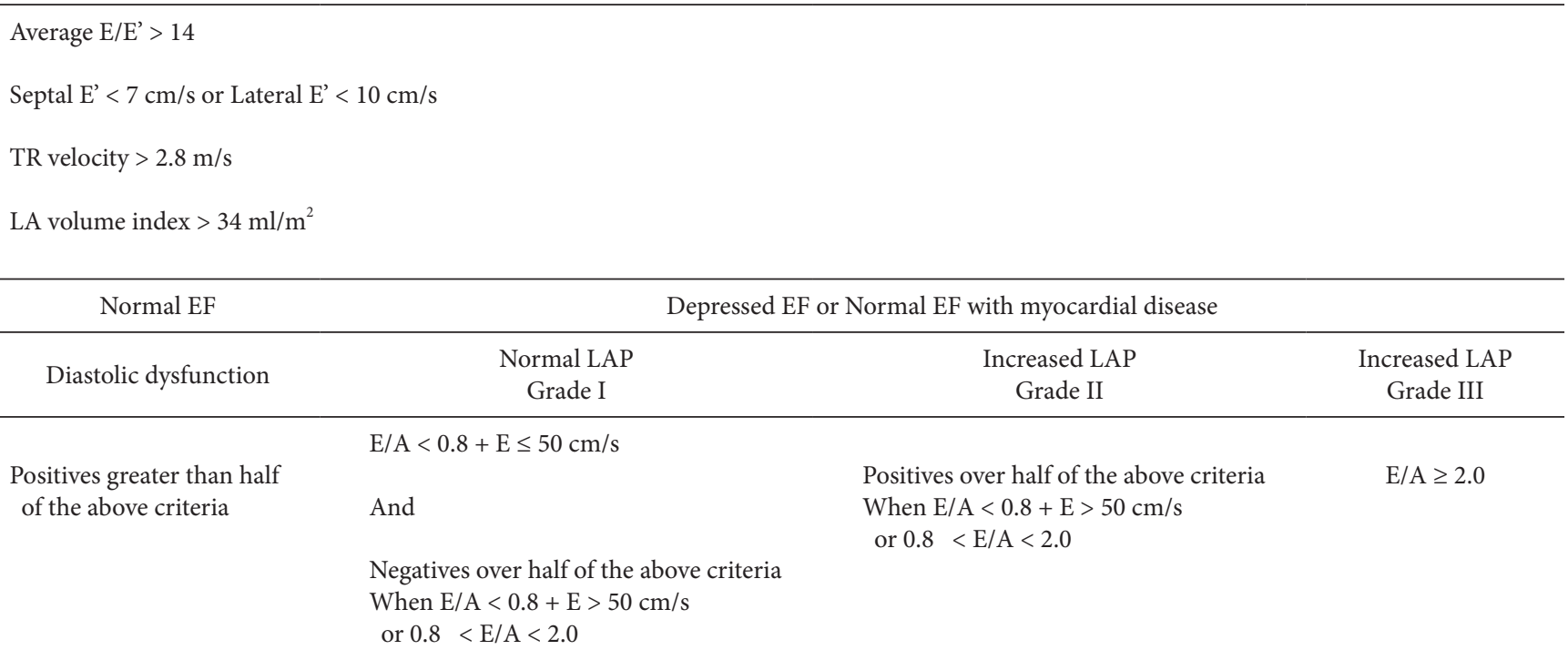

TR: tricuspid regurgitation, LA: left atrium, EF: ejection fraction, LAP: left atrial pressure. 
Some Doppler variables are valuable for the assessment of myocardial diastolic function including TMF with PWD (E/A wave, deceleration time [DT], A duration), pulmonary venous inflow with PWD (S/D, atrial reversal [Ar]), tissue Doppler image (TDI) with PWD (E'/A' wave), and transmitral color M-mode (TMF propagation velocity $[\mathrm{Vp}]$ ), usually on midesophageal (ME) four-chamber and ME long-axis views. Conventionally, the LV filling pattern of TMF (E and A wave, E/A ratio) and DT are most commonly used in echocardiographic examinations regarding DDf, but these, along with pulmonary venous flow patterns, are dependent on preload variation and heart rate and rhythm disturbances [52,53]. In this regard, the patient's preload can be reduced using nitroglycerin (NTG) or with the use of the Valsalva maneuver in an awake state (or reverse Trendelenburg position or a prolonged lung recruit maneuver in a patient under general anesthesia) potentially unmasking an E, A pattern and impaired relaxation to discriminate normal from a pseudo-normal state [8].

In contrast, tissue Doppler imaging of the mitral annulus is considered a more sensitive tool in the assessment of DDf, in which measurements of E' indicate the myocardial velocity, and not blood flow velocity. E' may be influenced by preload variation in the normal heart [54], but becomes preload-independent in a heart with DDf [55]. The abnormal range of E'values is also influenced by age: an $\mathrm{E}^{\prime}<10 \mathrm{~cm} / \mathrm{s}$ in those $<50$ years and $\mathrm{E}^{\prime}<8$ in those $>50$ [54]. The value of $E^{\prime}$ is higher at the lateral annulus than the septal annulus, because the motion of the lateral annulus is freer than that of the septal annulus due to the surrounding structures.

It is convenient to use the lateral E' in intraoperative TEE and the septal E' in TTE [56,57]. Measurements of E' represent the early diastolic active relaxation phase, but do not represent LV compliance for which the E/E' ratio (the ratio of the transmitral $\mathrm{E}$ wave velocity to the mitral annular velocity) normalizes early transmitral LV filling to mitral annular motion. This is used to estimate mean left atrial pressure, with values $>15$ representing elevated filling pressures and $<8$ reflecting normal filling pressures $[56,58,59]$. With a ratio between 8 and 15 , other Doppler variables should be considered to estimate LV filling pressure. This measurement has been considered accurate and relatively independent of LV systolic function, rhythm abnormalities, LV hypertrophy, and functional mitral regurgitation [58,60-62].

The prediction of LV filling pressure using Doppler modalities is important in patients with DDf. Elevated LV filling pressures may be the most important factor in poor outcomes, rather than merely the presence of delayed relaxation [63]. After cardiac surgery, it can also predict a prolonged ICU/hospital stay and mortality independently of systolic function [58,64]. When evaluating diastolic function with echocardiographic tools, measurements should be performed multiple times, considering multiple Doppler variables (Table 4).

According to these echocardiographic variables, based on TEE, it might be suggested that predictors for increased perioperative cardiovascular risk would include E/A of 1-2, DT of 150-200 ms, E' $<8 \mathrm{~cm} / \mathrm{s}, \mathrm{E} / \mathrm{E}^{\prime}>15, \mathrm{Vp}<40 \mathrm{~cm} / \mathrm{s}$, an enlarged LA, and LV hypertrophy in TTE. In fact, TDI is of limited use in analyzing regional wall motion abnormalities; however, there are some recent advances in color TDI, such as strain, strain rate, speckle tracking, and velocity vector imaging $[65,66]$ that may allow a better appreciation of LV filling dynamics and a more accurate classification of diastolic function.

Brain natriuretic peptide (BNP) and N-terminal proBNP (NT proBNP) are recognized as specific markers of heart failure (HF) with acute dyspnea [67] and are elevated in both HFpreEF and HF with reduced HF (HFrEF) [50]. These markers tend to be higher in HFrEF than HFpreEF, but do not distinguish HFpreEF from HFrEF effectively [68,69]. Suggested levels for a diagnosis of acute HF are BNP > $100 \mathrm{pg} / \mathrm{ml}$ or NT proBNP > $300 \mathrm{pg} / \mathrm{ml}$ [70], which are independent predictors of adverse cardiovascular events in HFpreEF [71]. BNP values should be considered in association with other confounding factors. Other reasons for elevated BNP factors include renal failure and pulmonary hypertension, caused by lung disease, and obesity, which decrease BNP levels. However, even a normal level does not rule out HFpreEF [72,73].

Table 4. Practical Echocardiographic Approach to Diastolic Function in Intraoperative TEE

\begin{tabular}{|c|c|c|}
\hline \multicolumn{3}{|c|}{ Septal $\mathrm{E}^{\prime}<7$, Lateral $\mathrm{E}^{\prime}<10$ or $\mathrm{Vp}<40 \mathrm{~cm} / \mathrm{s}$} \\
\hline $\begin{array}{c}\text { Grade I } \\
\text { (Impaired Relaxation) }\end{array}$ & $\begin{array}{c}\text { Grade II } \\
\text { (Pseudo-normal) }\end{array}$ & $\begin{array}{c}\text { Grade III } \\
\text { (Restrictive pattern) }\end{array}$ \\
\hline $\mathrm{E} / \mathrm{A}<0.8$ & E/A $0.8-2.0$ & $\mathrm{E} / \mathrm{A} \geq 2.0$ \\
\hline $\mathrm{DT}>200 \mathrm{~ms}$ & DT $160-200 \mathrm{~ms}$ & $\mathrm{DT}<160 \mathrm{~ms}$ \\
\hline Average $\mathrm{E} / \mathrm{E}^{\prime} \leq 8$ & Average E/E' 9-13 & Average E/E' $\geq 14$ \\
\hline Ar-Adur $<0 \mathrm{~m} / \mathrm{s}, \mathrm{S} / \mathrm{D}>1$ & Ar-Adur $\geq 30 \mathrm{~m} / \mathrm{s}, \mathrm{S} / \mathrm{D}<1$ & Ar-Adur $\geq 30 \mathrm{~m} / \mathrm{s}, \mathrm{S} / \mathrm{D}<1$ \\
\hline Valsalva $\Delta \mathrm{E} / \mathrm{A}<0.5$ & Valsalva $\Delta \mathrm{E} / \mathrm{A} \geq 0.5$ & Valsalva $\Delta \mathrm{E} / \mathrm{A} \geq 0.5$ \\
\hline
\end{tabular}

TEE: transesophageal echocardiography, Vp: propagation velocity, DT: deceleration time, Ar: pulmonary venous A-wave reversal wave, Adur: transmitral A-wave duration. 


\section{Perioperative Management}

As mentioned above, it is important not to overlook patients with asymptomatic LV DDf in the preoperative evaluations, and risk factors for heart failure should also be considered. Although not specific to geriatric patients, the latest ACC/AHA guidelines [6] should be used for the perioperative care of cardiac patients undergoing general surgery, and if needed, preoperative cardiovascular risk factors should be evaluated and treated by cardiologists. In ischemic heart disease-related procedures, bare-metal stenting can be performed with dual anti-platelet therapy for 4-6 weeks. Statins should not be discontinued before surgery. Because the renin-angiotensin-aldosterone system plays an important role in the development of DHF and particularly in myocardial remodeling and fluid retention, angiotensinconverting enzyme inhibitors, angiotensin receptor antagonists, and aldosterone antagonists have been proposed for treatment [74]. As aforementioned mentioned, drugs for the treatment of pre-existing heart failure, arrhythmias, hypertension, and ischemic heart diseases (e.g., diuretics, $\beta$-blockers, calcium channel blockers, antiplatelet agents) should be maintained during the perioperative period.

The principles of anesthetic management for patients with DDf must be addressed on a case-by-case basis. In addition to standard monitoring tools, monitoring the volume status in these patients is important, because they are very sensitive to volume changes due to surgical bleeding and sympathetic tone changes due to anesthesia in the perioperative period. Thus, instituting an arterial cannula is necessary for invasive arterial monitoring, indirect assessments of preload by stroke volume variance, and frequent blood sampling; the timing of each should be based on experience and local practice. In major or vascular surgery, central venous catheterization, pulmonary artery catheterization, and/or TEE may be needed, which can contribute to evaluating intravascular volume during anesthesia.

During anesthesia, patients with DDf or DHF are commonly elderly and may have hemodynamic instability because of general and regional anesthesia disturbing the baseline sympathetic tone, thereby leaving the patient with a higher resting sympathetic tone and altered $\beta$-receptor sensitivity. In addition, the frequent use of diuretics due to pre-existing diseases, a reduction in the thirst response in the elderly, and age-related renal function changes can aggravate the reduction of preload, increasing the sensitivity to volume status. Moreover, direct effects of anesthetics on cardiac inotropy and lusitropy as well as arterial and venous vasodilation cannot be ignored with regard to unstable hemodynamics either. The choice of regional versus general anesthesia is still debated and there are no definitive recommendations either way. However, epidural anesthesia is preferable to spinal anesthesia because of slower hemodynamic changes from the slow onset time and the smooth removal of sympathetic tone. In addition, for general anesthesia, IV induction and maintenance with balanced anesthesia of volatile agents and opioids are recommended.

There are limited clinical data on the effects of anesthetic drugs on diastolic function. Sevoflurane during spontaneous ventilation preserves diastolic relaxation better than propofol, but there are no differences between them regarding diastolic function during positive pressure ventilation through balanced anesthesia [75]. The common volatile agents (sevoflurane, desflurane, isoflurane), IV anesthetics (propofol, midazolam), and opioids (morphine, remifentanil) have no significant effects on diastolic performance in healthy people, unlike some animal models [76,77]. However, in high-risk DHF patients, anesthesiologists should avoid acute changes in hemodynamic load conditions, heart rate, and myocardial oxygen balance. To achieve this, a 30-50\% reduced dose of induction agents should be used, followed by waiting for their delayed effects due to the reduced cardiac reserve and slower circulation time, as well as titrating the anesthetics. Hypoxia, hypercarbia, and pulmonary hypertension should also be prevented.

Intraoperative BP control is important, in that systolic BP must be within $10-20 \%$ of the baseline value and PP should be kept below the diastolic BP. An increased PP increases ventricular wall stress, alters ventricular contraction time, and impairs early diastolic filling, increasing the cardiac workload. The "Rule of 70s" is useful for controlling BP: age $>70$, diastolic $\mathrm{BP}>70$, $\mathrm{HR}=70$, and $\mathrm{PP}<70$. Given the effects on cardiac work by controlling PP, the combined use of low-dose NTG $(0.5-4 \mu \mathrm{g} /$ $\mathrm{kg} / \mathrm{min}$ ) and phenylephrine titration (from $0.25 \mu \mathrm{g} / \mathrm{kg} / \mathrm{min}$ ) is applicable and helpful, but either agent alone can worsen hemodynamics. This protocol preserves vascular distensibility, and prevents reductions in preload and coronary perfusion pressure, thereby maintaining stroke volume with minimal cardiac work [8].

In the postoperative period in patients with known DDf, hypoxemia and/or atrial fibrillation are the most common com-

Table 5. Perioperative Precipitating Factors for Diastolic Heart Failure

Shivering
Anemia
Hypoxia
Electrolytic imbalance
Deterioration in diastolic dysfunction
Myocardial ischemia: directly affects relaxation and induces rhythm
disturbances
Hypovolemia or hypervolemia (extreme volume shifting)
Tachycardia
Rhythms other than sinus
Postoperative sympathetic stimulation
Postoperative hypertensive crisis


plications, because restored vascular sympathetic tone due to emergence and resolution from general or regional anesthesia causes a volume shift to central blood volume. The subsequent volume overload can result in pulmonary edema and/or atrial fibrillation due to decompensation. Because these events can happen acutely in a patient with an initially stable appearance, continued and careful monitoring are essential. Maintenance of NTG at a low dose ( $25 \mu \mathrm{g} / \mathrm{min})$ is also useful for the pulmonary vasculature, and it is important to avoid the risk factors that predispose patients to HF (Table 5). Among these factors, a hypertensive crisis can be managed with sound anesthetic practices, planning for appropriate postoperative analgesia, preventing shivering by control of body temperature during the operation, and using IV calcium channel blockers (nicardipine, diltiazem) and high doses of IV NTG.

Specific drugs with positive lusitropic effects are often invaluable in circulatory failure related to DDf and include phosphodiesterase III inhibitors (milrinone) and calcium channel sensitizers (levosimendan) [7], both of which are inodilators. Milrinone has inotropic, vasodilatory, and lusitropic (particularly in a heart failure state) effects with minimal chronotropy, by increasing calcium ion uptake in the sarcoplasmic reticulum. It can be used at a bolus dose of $50 \mu \mathrm{g} / \mathrm{kg}$ over $10 \mathrm{~min}$ and an infusion of $0.375-0.75 \mu \mathrm{g} / \mathrm{kg} / \mathrm{min}[7,11]$. Levosimendan sensitizes the contractile elements to calcium and has positive inotropic effects, modulating the interaction between troponin and calcium. It also has vasodilatory effects by opening ATP-sensitive potassium channels and improving both systolic and diastolic functions.

\section{Conclusions}

DDf of the LV and DHF with preserved EF are not rare pathologies, but are frequently underestimated. In the preoperative evaluation of asymptomatic patients undergoing high-risk surgery, echocardiographic assessment of LV diastolic function should be included in cardiovascular assessments, as should consideration of the risk factors for DHF. Early detection of and not overlooking preclinical LV diastolic dysfunction can be useful for the choice of appropriate surgery, appropriate BP control, timely monitoring tools, and proper volume management to maintain normovolemia on a case-by-case basis. Although anesthesiologists may not appreciate the stages of DDf, those who are involved in the perioperative care of these patients with cardiovascular disorders need to be able to manage them appropriately. Because there is not yet an evidence-based treatment of choice regarding acute decompensated DHF, its management should focus on resolving known precipitating factors such as myocardial ischemia, hypertensive crisis, arrhythmias, and pulmonary congestion.

\section{ORCID}

Taeha Ryu, http://orcid.org/0000-0002-5973-7715

Seok-Young Song, http://orcid.org/0000-0002-5653-7005

\section{References}

1. Rabuel C, Mebazaa A. Septic shock: a heart story since the 1960s. Intensive Care Med 2006; 32: 799-807.

2. Stugaard M, Smiseth OA, Risöe C, Ihlen H. Intraventricular early diastolic filling during acute myocardial ischemia, assessment by multigated color m-mode Doppler echocardiography. Circulation 1993; 88: 2705-13.

3. Higashita R, Sugawara M, Kondoh Y, Kawai Y, Mitsui K, Ohki S, et al. Changes in diastolic regional stiffness of the left ventricle before and after coronary artery bypass grafting. Heart Vessels 1996; 11: 145-51.

4. Castello R, Pearson AC, Kern MJ, Labovitz AJ. Diastolic function in patients undergoing coronary angioplasty: influence of degree of revascularization. J Am Coll Cardiol 1990; 15: 1564-9.

5. Rooke GA. Cardiovascular aging and anesthetic implications. J Cardiothorac Vasc Anesth 2003; 17: 512-23.

6. Fleisher LA, Fleischmann KE, Auerbach AD, Barnason SA, Beckman JA, Bozkurt B, et al. 2014 ACC/AHA guideline on perioperative cardiovascular evaluation and management of patients undergoing noncardiac surgery: a report of the American College of Cardiology/ American Heart Association Task Force on practice guidelines. J Am Coll Cardiol 2014; 64: e77-137.

7. Pirracchio R, Cholley B, De Hert S, Solal AC, Mebazaa A. Diastolic heart failure in anaesthesia and critical care. Br J Anaesth 2007; 98: 70721.

8. Sanders D, Dudley M, Groban L. Diastolic dysfunction, cardiovascular aging, and the anesthesiologist. Anesthesiol Clin 2009; $27: 497-517$.

9. Paulus WJ, Tschöpe C, Sanderson JE, Rusconi C, Flachskampf FA, Rademakers FE, et al. How to diagnose diastolic heart failure: a consensus statement on the diagnosis of heart failure with normal left ventricular ejection fraction by the Heart Failure and Echocardiography Associations of the European Society of Cardiology. Eur Heart J 2007; 28: 2539-50.

10. Groban L, Kitzman DW. Diastolic function: a barometer for cardiovascular risk? Anesthesiology. 2010; 112: 1303-6.

11. Maharaj R. Diastolic dysfunction and heart failure with a preserved ejection fraction: Relevance in critical illness and anaesthesia. J Saudi Heart Assoc 2012; 24: 99-121. 
12. Correa de Sa DD, Hodge DO, Slusser JP, Redfield MM, Simari RD, Burnett JC, et al. Progression of preclinical diastolic dysfunction to the development of symptoms. Heart 2010; 96: 528-32.

13. Redfield MM, Jacobsen SJ, Burnett JC Jr, Mahoney DW, Bailey KR, Rodeheffer RJ. Burden of systolic and diastolic ventricular dysfunction in the community: appreciating the scope of the heart failure epidemic. JAMA 2003; 289: 194-202.

14. Kitzman DW, Gardin JM, Gottdiener JS, Arnold A, Boineau R, Aurigemma G, et al. Importance of heart failure with preserved systolic function in patients $>$ or $=65$ years of age. CHS Research Group. Cardiovascular Health Study. Am J Cardiol 2001; 87: 413-9.

15. Owan TE, Hodge DO, Herges RM, Jacobsen SJ, Roger VL, Redfield MM. Trends in prevalence and outcome of heart failure with preserved ejection fraction. N Engl J Med 2006; 355: 251-9.

16. Vasan RS, Larson MG, Benjamin EJ, Evans JC, Reiss CK, Levy D. Congestive heart failure in subjects with normal versus reduced left ventricular ejection fraction: prevalence and mortality in a population-based cohort. J Am Coll Cardiol 1999; 33: 1948-55.

17. Liao L, Jollis JG, Anstrom KJ, Whellan DJ, Kitzman DW, Aurigemma GP, et al. Costs for heart failure with normal vs reduced ejection fraction. Arch Intern Med 2006; 166: 112-8.

18. Masoudi FA, Havranek EP, Smith G, Fish RH, Steiner JF, Ordin DL, et al. Gender, age, and heart failure with preserved left ventricular systolic function. J Am Coll Cardiol 2003; 41: 217-23.

19. Phillip B, Pastor D, Bellows W, Leung JM. The prevalence of preoperative diastolic filling abnormalities in geriatric surgical patients. Anesth Analg 2003; 97: 1214-21.

20. Matyal R, Hess PE, Subramaniam B, Mitchell J, Panzica PJ, Pomposelli F, et al. Perioperative diastolic dysfunction during vascular surgery and its association with postoperative outcome. J Vasc Surg 2009; 50: 70-6.

21. Zile MR, Brutsaert DL. New concepts in diastolic dysfunction and diastolic heart failure: Part I: diagnosis, prognosis, and measurements of diastolic function. Circulation 2002; 105: 1387-93.

22. Nishimura RA, Tajik AJ. Evaluation of diastolic filling of left ventricle in health and disease: Doppler echocardiography is the clinician's Rosetta Stone. J Am Coll Cardiol 1997; 30: 8-18.

23. Gillebert TC, Leite-Moreira AF, De Hert SG. Relaxation-systolic pressure relation. A load-independent assessment of left ventricular contractility. Circulation 1997; 95: 745-52.

24. Betocchi S, Piscione F, Villari B, Pace L, Ciarmiello A, Perrone-Filardi P, et al. Effects of induced asynchrony on left ventricular diastolic function in patients with coronary artery disease. J Am Coll Cardiol 1993; 21: 1124-31.

25. Mirsky I. Assessment of diastolic function: suggested methods and future considerations. Circulation 1984; 69: 836-41.

26. van Heerebeek L, Borbély A, Niessen HW, Bronzwaer JG, van der Velden J, Stienen GJ, et al. Myocardial structure and function differ in systolic and diastolic heart failure. Circulation 2006; 113: 1966-73.

27. Lee TH, Marcantonio ER, Mangione CM, Thomas EJ, Polanczyk CA, Cook EF, et al. Derivation and prospective validation of a simple index for prediction of cardiac risk of major noncardiac surgery. Circulation 1999; 100: 1043-9.

28. Lakatta EG. Arterial and cardiac aging: major shareholders in cardiovascular disease enterprises: Part III: cellular and molecular clues to heart and arterial aging. Circulation 2003; 107: 490-7.

29. Kawaguchi M, Hay I, Fetics B, Kass DA. Combined ventricular systolic and arterial stiffening in patients with heart failure and preserved ejection fraction: implications for systolic and diastolic reserve limitations. Circulation 2003; 107: 714-20.

30. Abhayaratna WP, Barnes ME, O'Rourke MF, Gersh BJ, Seward JB, Miyasaka Y, et al. Relation of arterial stiffness to left ventricular diastolic function and cardiovascular risk prediction in patients > or =65 years of age. Am J Cardiol 2006; 98: 1387-92.

31. Lakatta EG, Levy D. Arterial and cardiac aging: major shareholders in cardiovascular disease enterprises: Part I: aging arteries: a "set up" for vascular disease. Circulation 2003; 107: 139-46.

32. Mitchell GF, Parise H, Benjamin EJ, Larson MG, Keyes MJ, Vita JA, et al. Changes in arterial stiffness and wave reflection with advancing age in healthy men and women: the Framingham Heart Study. Hypertension 2004; 43: 1239-45.

33. Gillebert TC, Leite-Moreira AF, De Hert SG. Load dependent diastolic dysfunction in heart failure. Heart Fail Rev 2000; 5: 345-55.

34. Leite-Moreira AF, Correia-Pinto J, Gillebert TC. Afterload induced changes in myocardial relaxation: a mechanism for diastolic dysfunction. Cardiovasc Res 1999; 43: 344-53.

35. Meaume S, Benetos A, Henry OF, Rudnichi A, Safar ME. Aortic pulse wave velocity predicts cardiovascular mortality in subjects $>70$ years of age. Arterioscler Thromb Vasc Biol 2001; 21: 2046-50.

36. Chae CU, Pfeffer MA, Glynn RJ, Mitchell GF, Taylor JO, Hennekens CH. Increased pulse pressure and risk of heart failure in the elderly. JAMA 1999; 281: 634-9.

37. Franklin SS, Khan SA, Wong ND, Larson MG, Levy D. Is pulse pressure useful in predicting risk for coronary heart Disease? The Framingham heart study. Circulation 1999; 100: 354-60.

38. Domanski M, Norman J, Wolz M, Mitchell G, Pfeffer M. Cardiovascular risk assessment using pulse pressure in the first national health and nutrition examination survey (NHANES I). Hypertension 2001; 38: 793-7.

39. Cain BS, Meldrum DR, Joo KS, Wang JF, Meng X, Cleveland JC Jr, et al. Human SERCA2a levels correlate inversely with age in senescent human myocardium. J Am Coll Cardiol 1998; 32: 458-67.

40. Schmidt U, del Monte F, Miyamoto MI, Matsui T, Gwathmey JK, Rosenzweig A, et al. Restoration of diastolic function in senescent rat hearts through adenoviral gene transfer of sarcoplasmic reticulum Ca(2+)-ATPase. Circulation 2000; 101: 790-6. 
41. Assayag P, CHarlemagne D, Marty I, de Leiris J, Lompré AM, Boucher F, et al. Effects of sustained low-flow ischemia on myocardial function and calcium-regulating proteins in adult and senescent rat hearts. Cardiovasc Res 1998; 38: 169-80.

42. Lakatta EG, Sollott SJ. Perspectives on mammalian cardiovascular aging: humans to molecules. Comp Biochem Physiol A Mol Integr Physiol 2002; 132: 699-721.

43. Davies CH, Ferrara N, Harding SE. Beta-adrenoceptor function changes with age of subject in myocytes from non-failing human ventricle. Cardiovasc Res 1996; 31: 152-6.

44. White M, Roden R, Minobe W, Khan MF, Larrabee P, Wollmering M, et al. Age-related changes in beta-adrenergic neuroeffector systems in the human heart. Circulation 1994; 90: 1225-38.

45. Aronow WS, Ahn C, Kronzon I. Effect of propranolol versus no propranolol on total mortality plus nonfatal myocardial infarction in older patients with prior myocardial infarction, congestive heart failure, and left ventricular ejection fraction $>$ or $=40 \%$ treated with diuretics plus angiotensin-converting enzyme inhibitors. Am J Cardiol 1997; 80: 207-9.

46. Setaro JF, Zaret BL, Schulman DS, Black HR, Soufer R. Usefulness of verapamil for congestive heart failure associated with abnormal left ventricular diastolic filling and normal left ventricular systolic performance. Am J Cardiol 1990; 66: 981-6.

47. Matyal R, Skubas NJ, Shernan SK, Mahmood F. Perioperative assessment of diastolic dysfunction. Anesth Analg 2011; 113: 449-72.

48. Rakowski H, Appleton C, Chan KL, Dumesnil JG, Honos G, Jue J, et al. Canadian consensus recommendations for the measurement and reporting of diastolic dysfunction by echocardiography: from the Investigators of Consensus on Diastolic Dysfunction by Echocardiography. J Am Soc Echocardiogr 1996; 9: 736-60.

49. Appleton CP, Jensen JL, Hatle LK, Oh JK. Doppler evaluation of left and right ventricular diastolic function: a technical guide for obtaining optimal flow velocity recordings. J Am Soc Echocardiogr 1997; 10: 271-92.

50. Cohen GI, Pietrolungo JF, Thomas JD, Klein AL. A practical guide to assessment of ventricular diastolic function using Doppler echocardiography. J Am Coll Cardiol 1996; 27: 1753-60.

51. Nagueh SF, Smiseth OA, Appleton CP, Byrd BF 3rd, Dokainish H, Edvardsen T, et al. Recommendations for the Evaluation of Left Ventricular Diastolic Function by Echocardiography: An Update from the American Society of Echocardiography and the European Association of Cardiovascular Imaging. J Am Soc Echocardiogr 2016; 29: 277-314.

52. Garcia MJ, Smedira NG, Greenberg NL, Main M, Firstenberg MS, Odabashian J, et al. Color M-mode Doppler flow propagation velocity is a preload insensitive index of left ventricular relaxation: animal and human validation. J Am Coll Cardiol 2000; 35: 201-8.

53. Møller JE, Poulsen SH, Søndergaard E, Egstrup K. Preload dependence of color M-mode Doppler flow propagation velocity in controls and in patients with left ventricular dysfunction. J Am Soc Echocardiogr 2000; 13: 902-9.

54. Skubas N. Intraoperative Doppler tissue imaging is a valuable addition to cardiac anesthesiologists' armamentarium: a core review. Anesth Analg 2009; 108: 48-66.

55. Firstenberg MS, Greenberg NL, Main ML, Drinko JK, Odabashian JA, Thomas JD, et al. Determinants of diastolic myocardial tissue Doppler velocities: influences of relaxation and preload. J Appl Physiol (1985) 2001; 90: 299-307.

56. Nagueh SF, Middleton KJ, Kopelen HA, Zoghbi WA, Quiñones MA. Doppler tissue imaging: a noninvasive technique for evaluation of left ventricular relaxation and estimation of filling pressures. J Am Coll Cardiol 1997; 30: 1527-33.

57. Mullens W, Borowski AG, Curtin RJ, Thomas JD, Tang WH. Tissue Doppler imaging in the estimation of intracardiac filling pressure in decompensated patients with advanced systolic heart failure. Circulation 2009; 119: 62-70.

58. Møller JE, Pellikka PA, Hillis GS, Oh JK. Prognostic importance of diastolic function and filling pressure in patients with acute myocardial infarction. Circulation 2006; 114: 438-44.

59. Ommen SR, Nishimura RA, Appleton CP, Miller FA, Oh JK, Redfield MM, et al. Clinical utility of Doppler echocardiography and tissue Doppler imaging in the estimation of left ventricular filling pressures: A comparative simultaneous Doppler-catheterization study. Circulation 2000; 102: 1788-94.

60. Nagueh SF, Mikati I, Kopelen HA, Middleton KJ, Quiñones MA, Zoghbi WA. Doppler estimation of left ventricular filling pressure in sinus tachycardia. A new application of tissue doppler imaging. Circulation 1998; 98: 1644-50.

61. Nagueh SF, Lakkis NM, Middleton KJ, Spencer WH 3rd, Zoghbi WA, Quiñones MA. Doppler estimation of left ventricular filling pressures in patients with hypertrophic cardiomyopathy. Circulation 1999; 99: 254-61.

62. Bruch C, Stypmann J, Gradaus R, Breithardt G, Wichter T. Usefulness of tissue Doppler imaging for estimation of filling pressures in patients with primary or secondary pure mitral regurgitation. Am J Cardiol 2004; 93: 324-8.

63. Møller JE, Søndergaard E, Poulsen SH, Egstrup K. Pseudonormal and restrictive filling patterns predict left ventricular dilation and cardiac death after a first myocardial infarction: a serial color M-mode Doppler echocardiographic study. J Am Coll Cardiol 2000; 36: 1841-6.

64. Salem R, Denault AY, Couture P, Bélisle S, Fortier A, Guertin MC, et al. Left ventricular end-diastolic pressure is a predictor of mortality in cardiac surgery independently of left ventricular ejection fraction. Br J Anaesth 2006; 97: 292-7.

65. Gorcsan J 3rd, Tanaka H. Echocardiographic assessment of myocardial strain. J Am Coll Cardiol 2011; 58: 1401-13.

66. Mor-Avi V, Lang RM, Badano LP, Belohlavek M, Cardim NM, Derumeaux G, et al. Current and evolving echocardiographic techniques for the quantitative evaluation of cardiac mechanics: ASE/EAE consensus statement on methodology and indications endorsed by the Japanese Society of Echocardiography. J Am Soc Echocardiogr 2011; 24: 277-313.

67. Morrison LK, Harrison A, Krishnaswamy P, Kazanegra R, Clopton P, Maisel A. Utility of a rapid B-natriuretic peptide assay in 
differentiating congestive heart failure from lung disease in patients presenting with dyspnea. J Am Coll Cardiol 2002; 39: 202-9.

68. Maisel AS, McCord J, Nowak RM, Hollander JE, Wu AH, Duc P, et al. Bedside B-Type natriuretic peptide in the emergency diagnosis of heart failure with reduced or preserved ejection fraction. Results from the Breathing Not Properly Multinational Study. J Am Coll Cardiol 2003; 41: 2010-7.

69. van Veldhuisen DJ, Linssen GC, Jaarsma T, van Gilst WH, Hoes AW, Tijssen JG, et al. B-type natriuretic peptide and prognosis in heart failure patients with preserved and reduced ejection fraction. J Am Coll Cardiol 2013; 61: 1498-506.

70. McMurray JJ, Adamopoulos S, Anker SD, Auricchio A, Böhm M, Dickstein K, et al. ESC Guidelines for the diagnosis and treatment of acute and chronic heart failure 2012: The Task Force for the Diagnosis and Treatment of Acute and Chronic Heart Failure 2012 of the European Society of Cardiology. Developed in collaboration with the Heart Failure Association (HFA) of the ESC. Eur Heart J 2012; 33: $1787-847$.

71. Grewal J, McKelvie RS, Persson H, Tait P, Carlsson J, Swedberg K, et al. Usefulness of N-terminal pro-brain natriuretic Peptide and brain natriuretic peptide to predict cardiovascular outcomes in patients with heart failure and preserved left ventricular ejection fraction. Am $\mathrm{J}$ Cardiol 2008; 102: 733-7.

72. Borlaug BA, Nishimura RA, Sorajja P, Lam CS, Redfield MM. Exercise hemodynamics enhance diagnosis of early heart failure with preserved ejection fraction. Circ Heart Fail 2010; 3: 588-95.

73. Andersen MJ, Olson TP, Melenovsky V, Kane GC, Borlaug BA. Differential hemodynamic effects of exercise and volume expansion in people with and without heart failure. Circ Heart Fail 2015; 8: 41-8.

74. Chinnaiyan KM, Alexander D, McCullough PA. Role of angiotensin II in the evolution of diastolic heart failure. J Clin Hypertens (Greenwich) 2005; 7: 740-7.

75. Filipovic M, Michaux I, Wang J, Hunziker P, Skarvan K, Seeberger M. Effects of sevoflurane and propofol on left ventricular diastolic function in patients with pre-existing diastolic dysfunction. Br J Anaesth 2007; 98: 12-8.

76. Sarkar S, GuhaBiswas R, Rupert E. Echocardiographic evaluation and comparison of the effects of isoflurane, sevoflurane and desflurane on left ventricular relaxation indices in patients with diastolic dysfunction. Ann Card Anaesth 2010; 13: 130-7.

77. Bolliger D, Seeberger MD, Kasper J, Skarvan K, Seeberger E, Lurati Buse G, et al. Remifentanil does not impair left ventricular systolic and diastolic function in young healthy patients. Br J Anaesth 2011; 106: 573-9. 